\title{
Shifts in tourists' sentiments and climate risk perceptions following mass coral bleaching of the Great Barrier Reef
}

\author{
Matthew I. Curnock $\oplus^{1 \star}$, Nadine A. Marshall', Lauric Thiault $\oplus^{2,3}$, Scott F. Heron ${ }^{1,4,5}$, Jessica Hoey ${ }^{6}$, \\ Genevieve Williams ${ }^{1,6}$, Bruce Taylor ${ }^{7}$, Petina L. Pert ${ }^{1}{ }^{1}$ and Jeremy Goldberg ${ }^{1,8}$
}

Iconic places, including World Heritage areas, are symbolic and synonymous with national and cultural identities. Recognition of an existential threat to an icon may therefore arouse public concern and protective sentiment. Here we test this assumption by comparing sentiments, threat perceptions and values associated with the Great Barrier Reef and climate change attitudes among 4,681 Australian and international tourists visiting the Great Barrier Reef region before and after mass coral bleaching in $\mathbf{2 0 1 6}$ and 2017. There was an increase in grief-related responses and decline in self-efficacy, which could inhibit individual action. However, there was also an increase in protective sentiments, ratings of place values and the proportion of respondents who viewed climate change as an immediate threat. These results suggest that imperilled icons have potential to mobilize public support around addressing the wider threat of climate change but that achieving and sustaining engagement will require a strategic approach to overcome self-efficacy barriers.

G lobal warming threatens ecosystems and societies globally. However, in many countries public attitudes and perceptions of climate risks have lagged behind the accumulation of scientific evidence and assessments, contributing to inadequate political support for mitigation or adaptation ${ }^{1-3}$. As the risks and costs of climate change will increase the longer mitigation is delayed ${ }^{4}$, there is a need to understand barriers to public engagement with the issue and support for public action, including drivers of risk perceptions.

Many contextual and cultural factors can influence individuals climate change beliefs and attitudes, including value orientations, social identity and group norms ${ }^{5}$. While acceptance of the scientific consensus on human-induced climate change has been identified as an important 'gateway belief' to increased support for climate actions $s^{6}$, simply presenting more scientific facts to a sceptical or unengaged audience can be ineffective and even counterproductive $^{7}$. Changing attitudes, beliefs and value orientations requires both cognitive and affective engagement (that is, reasoned understanding combined with emotional consequence), with emotion regarded to have the greater influence ${ }^{3,8,9}$. Yet failure to elicit an affective response to the threat of climate change is common among climate and behaviour change campaigns ${ }^{10}$. Part of this problem is a widespread perception that climate change is an abstract threat, with distant impacts that are presumed to affect other people, in other places at a future time ${ }^{11-13}$.

Research that seeks to understand the processes by which climate change risks become more salient to people has become an important field of enquiry. Climate change awareness and risk perceptions can be influenced through affective stimuli and the emotional responses associated with the perceived threat of loss or harm to oneself and/or things that are valued ${ }^{5,14}$. The effectiveness of emotional appeals and of evoking specific emotions to promote public engagement in environmental issues and behaviour change is an ongoing subject of scholarly debates ${ }^{15}$. Discrete emotions that have been identified as strongly associated with increased support for climate change policy include worry, interest and hope ${ }^{14}$. Eliciting fear can result in attitudinal changes and motivate new behaviours in response to a perceived threat ${ }^{15,16}$; however, fear has also been shown to negatively influence engagement with the climate change issue and is considered detrimental to self-efficacy (the belief in one's ability to affect change $)^{9,14,17}$.

One approach to fostering improved engagement with climate change is the use and portrayal of icons. Icons are potent in their appeal to personal values and emotions; as such, they play an important role in representing climate change ${ }^{18,19}$. Iconic entities, including various animals, plants, natural and human-made landmarks, landscapes and ecosystems are symbolic, highly valued in numerous ways, and are synonymous with national and cultural identities ${ }^{20}$. Climate icons have been defined as "tangible entities which will be impacted by climate change, which the viewer considers worthy of respect, and to which the viewer can relate and feel empathy" ${ }^{17}$. Studies on the affective appeal of climate icons have used focus groups and workshops to identify characteristics that contribute to higher engagement ${ }^{9,17,18}$. However, affective responses associated with a large-scale climate impact to an iconic entity have not previously been documented.

In addition, an emerging body of literature on the 'science of loss' has highlighted an increasing need for research that explains the range of human values associated with the natural world, and

${ }^{1}$ CSIRO Land and Water, James Cook University, Townsville, Queensland, Australia. ${ }^{2}$ National Center for Scientific Research, PSL Université Paris, CRIOBE USR3278 CNRS-EPHE-UPVD, Paris, France. ${ }^{3}$ Laboratoire d'Excellence CORAIL, Papetoai Moorea, French Polynesia. ${ }^{4}$ Coral Reef Watch, US National

Oceanic and Atmospheric Administration, College Park, MD, USA. ${ }^{5}$ Marine Geophysical Laboratory, Physics, College of Science and Engineering, James Cook University, Townsville, Queensland, Australia. ${ }^{6}$ Great Barrier Reef Marine Park Authority, Townsville, Queensland, Australia. ${ }^{7} \mathrm{CSIRO}$ Land and Water, Brisbane, Queensland, Australia. ${ }^{8}$ College of Business, Law and Governance, James Cook University, Townsville, Queensland, Australia.

*e-mail: matt.curnock@csiro.au 
how these values are endangered by a changing climate ${ }^{21,22}$. While the prospect of icons becoming damaged or degraded might prompt evaluations of tangible and direct economic losses, there are many intangible and non-economic values for icons that are likely to remain insufficiently accounted for (for example, cultural, lifestyle, health and identity values) ${ }^{22}$. The incomplete recognition of these intangible values, and of how heterogeneous communities will be affected by an icon's loss or damage, increases the risk of failure to anticipate limits to adaptation, and to distinguish between acceptable, tolerable and intolerable outcomes ${ }^{22,23}$.

The Great Barrier Reef (GBR) is an iconic ecosystem and is regarded as Australia's 'most inspiring' icon ${ }^{24}$. It is part of the national cultural identity and its UNESCO World Heritage status is a source of pride for most Australians ${ }^{24,25}$. Place attachment, pride and place values (for example, aesthetic, biodiversity, scientific heritage and lifestyle values) for the GBR extend to communities of stakeholders internationally ${ }^{26,27}$ and contribute to the GBR's appeal as an international tourism attraction ${ }^{28}$. Physical and aesthetic attributes of the GBR that motivate tourists to visit and that contribute to their satisfaction with reef-based activities (for example, snorkelling, scuba diving and wildlife watching), include the perception of healthy corals, abundant fish and clear water ${ }^{29}$. Tourism has become the GBR's largest direct economic contributor, providing more than 58,000 sectoral jobs (full-time equivalent) and generating an estimated AUD $\$ 5.7$ billion annually; the GBR's total economic, social and icon asset value has been estimated at AUD\$56 billion ${ }^{30}$.

However, the GBR faces multiple, cumulative threats, including climate change, and its long-term outlook has been assessed as poor and getting worse ${ }^{31}$. The 2016 marine heatwave caused the most intense coral bleaching observed on the GBR and resulted in an estimated $29-30 \%$ loss of shallow coral cover ${ }^{32}$. The following summer, unprecedented back-to-back coral bleaching caused an estimated $20 \%$ of additional coral mortality ${ }^{33}$. Most of the severe bleaching occurred in the northern half of the GBR Marine Park, affecting many tourism sites in the Cairns region ${ }^{34}$. Additionally, in March 2017, a severe tropical cyclone damaged reef and island tourism sites in the Whitsundays region ${ }^{35}$. Future projections of heat stress under a business-as-usual scenario (representative concentration pathway RCP 8.5) represent an existential threat to the GBR and to coral reefs globally, with severe coral bleaching expected to occur annually from the mid-2040s (ref. ${ }^{36}$ ).

News of impacts to the GBR over 2016-2017 were reported internationally and a large proportion of those media stories were sensationalized and fatalistic in their messaging ${ }^{37}$. There were concerns that this negative media coverage would lead to a decline in tourist visits to the region ${ }^{38}$ and propagate perceptions that no effective action to save the GBR is possible ${ }^{37}$. Records of visits to the GBR indicate that general decline in tourist visits has not yet occurred ${ }^{39}$; instead, there has been an increase in 'last chance tourism', characterized by the motivation to see an iconic place (or species) before it is gone or permanently changed ${ }^{40}$.

In this study, we present results from surveys of 4,681 tourists (53\% Australian and 47\% international) who visited the GBR region before and after the events of 2016-2017 described above (see Methods). We show that imperilled icons can contribute to proximizing the climate change issue across scales by comparing tourists' affective responses and place values associated with an icon, their perceptions of threats to those values and their protective sentiment and self-efficacy, before $(2013, n=2,877)$ and after $(2017, n=1,804)$ the icon was subjected to a large-scale climatic impact.

\section{Emotional responses to the GBR}

We found a significant increase in the use of negatively valenced emotional words from 2013 to 2017 in response to the open-ended question, "what are the first words that come to mind when you think about the GBR?" (Fig. 1a,b). In particular, words associated with sadness (for example, 'fragile' and 'disappointing'), disgust (for example, 'pollution' and 'ruined'), anger (for example, 'destruction' and 'damage') and fear (for example, 'change' and 'danger') increased significantly, while words evoking neutral or positive emotions did not change (Fig. 1c). We compared the use of emotive words provided by tourists who had visited the GBR $(n=3,121)$ with words of those who had not visited the GBR at the time they were surveyed $(n=1,560)$. There was no difference in the use of such words between the two groups (Fig. 1c), suggesting that the emotive response was not dependent on personal experience and observation of GBR impacts.

Elements of the negative emotional content of responses in 2017 (Fig. 1b,c) were consistent with 'ecological grief', characterized as "the grief felt in relation to experienced or anticipated ecological losses, including the loss of species, ecosystems and meaningful landscapes due to acute or chronic environmental change" ${ }^{41}$. Sadness, anger and fear are common emotional reactions to many different types of loss, contributing to diverse grief responses ${ }^{42}$. Disgust is a primitive behaviour-influencing emotion that also occurs in a variety of contexts, including in response to politically oriented stimuli $^{43}$. Ecological grief is increasingly being recognized among the unquantified and intangible costs of ecological losses associated with the Anthropocene ${ }^{41,44,45}$. A related study reported 'reef grief' as a response to the 2016-2017 GBR coral bleaching event among local coastal residents and tourists, and found that ratings of place attachment, place identity, place-based pride, lifestyle dependence and derived wellbeing are associated with stronger expressions of ecological grief ${ }^{46}$. Our results here (Fig. 1) provide further insights into the emotional manifestation of ecological grief in this context. As non-local actors, tourists would not normally be considered to have strong lifestyle dependence on the destinations and attractions they visit; however, their place attachment for an icon such as the GBR can still be strong ${ }^{25,26}$ and they are vulnerable to experiencing grief in response to the icon's loss or damage.

\section{Threat perceptions and climate change attitudes}

In short, open-ended responses to the question "what do you think are the three most serious threats to the GBR?", the proportion of respondents identifying climate change increased from $40 \%$ of respondents in 2013 to $51 \%$ in 2017 , making climate change the most frequently cited threat overall in 2017 (Fig. 2a). In comparison, in 2013 the most commonly identified threat to the GBR was tourism (43\% of respondents), which dropped to third-ranked in 2017 (27\% of respondents). The pollution category included a wide range of responses (for example, litter, marine debris and urban pollutants) and was identified in 2017 by $50 \%$ of respondents. In 2017, pollution ranked second: up from being ranked third in 2013 at 30\%, potentially reflecting an increased awareness of the threat of marine debris. The other category that displayed a notable increase was effects of humanity ( $9 \%$ in 2013 to $24 \%$ in 2017), which included responses such as overpopulation, human activity and anthropogenic threats. Coral bleaching was cited by $8 \%$ of respondents in both years; however, its ranking relative to other perceived threats increased from eleventh in 2013 to ninth in 2017.

Public perceptions of environmental risks and threats are shaped by social, cultural and psychological processes, and the exchange of information about 'risk events' can amplify (or attenuate) public responses to a risk or threat ${ }^{47}$. Symbols and imagery portraying risk events further interact with these processes in ways that can intensify risk perceptions ${ }^{48}$. Public awareness and perceptions of threats facing the GBR have evolved in recent decades and media representations of threats and risk events are considered to have had influence ${ }^{37,49}$. Ironically, tourists perceive their own activities as a dominant impact at ecologically sensitive $\operatorname{sites}^{50}$. The presence of other tourists, associated infrastructure and localized site degradation are often the only pressures and impacts readily 


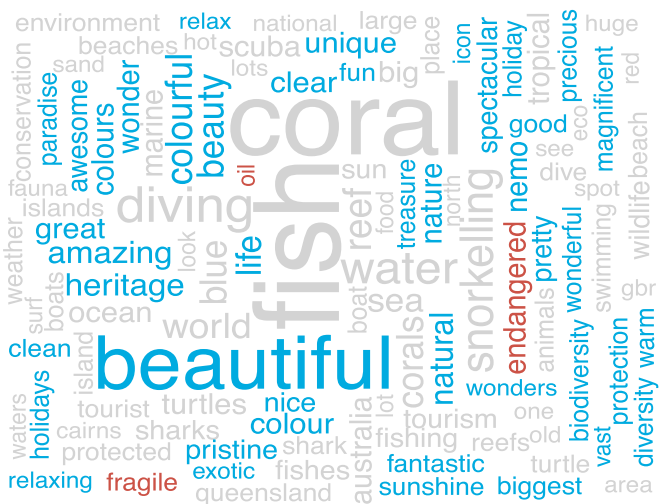

b

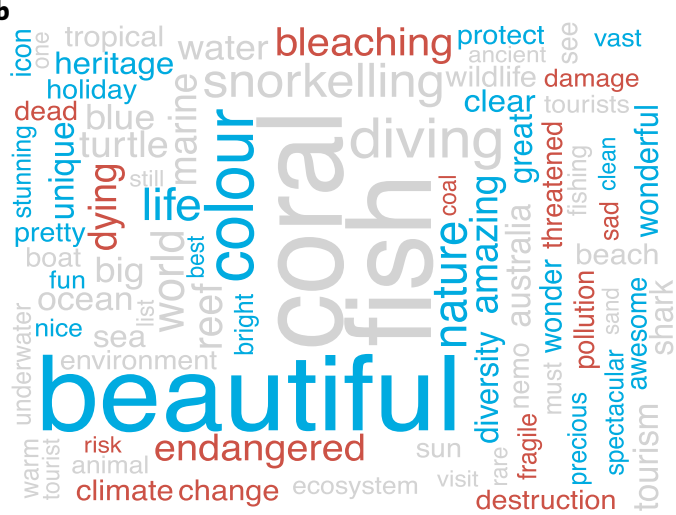

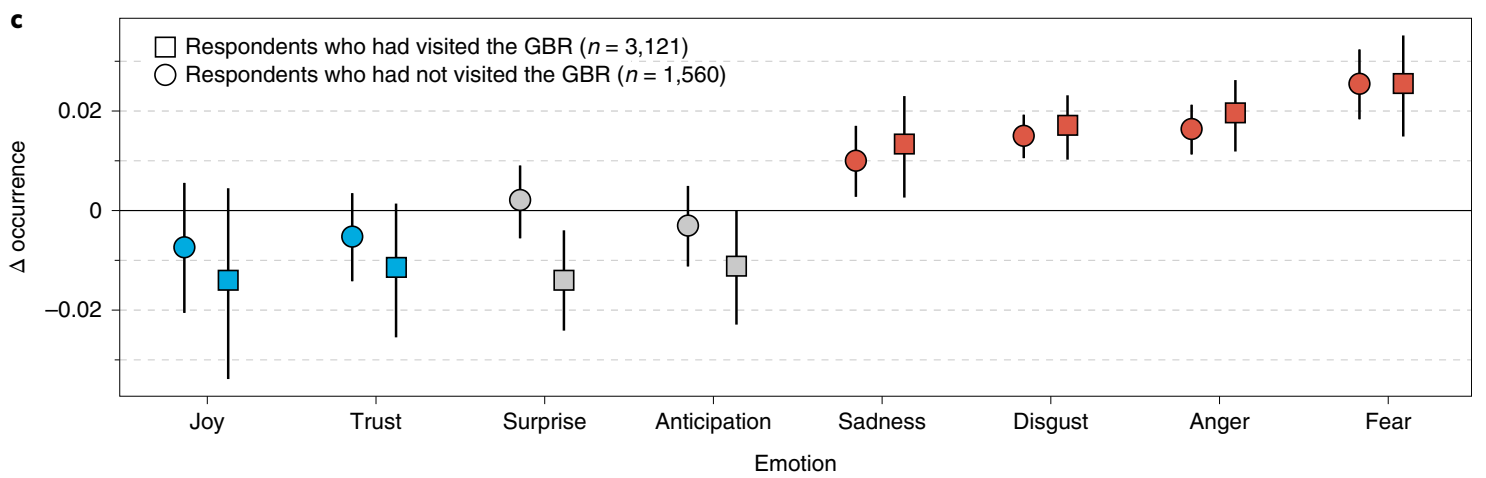

Fig. 1 Emotional words associated with the GBR. a,b, Visual comparisons of "the first words that come to mind when you think of the GBR" among tourists in the GBR region in 2013 ( $n=2,877)$ (a) and $2017(n=1,804)$ (b). The size of words represents the relative frequency of responses. Words with positive and negative valence are coloured in blue and red, respectively. Neutral words are shown in grey. Words occurring fewer than three times are omitted. c, Mean change in occurrence of positive (blue), negative (red) and neutral (grey) emotions associated with responses from 2013 to 2017 in respondents who had visited the GBR $(n=3,121)$ compared with those who had not $(n=1,560)$. Error bars show $95 \%$ confidence intervals. Changes in the occurrence of specific emotions are significant if the confidence interval does not overlap with the 2013 (zero) baseline.

\section{a}

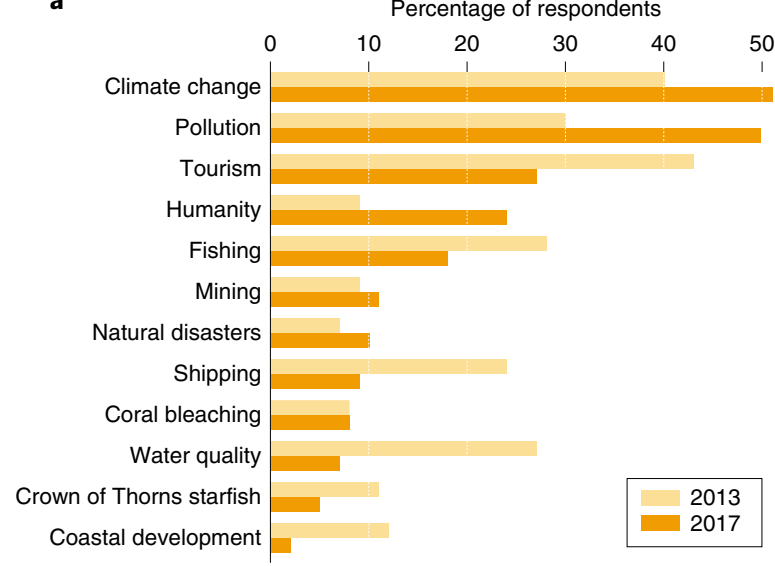

b

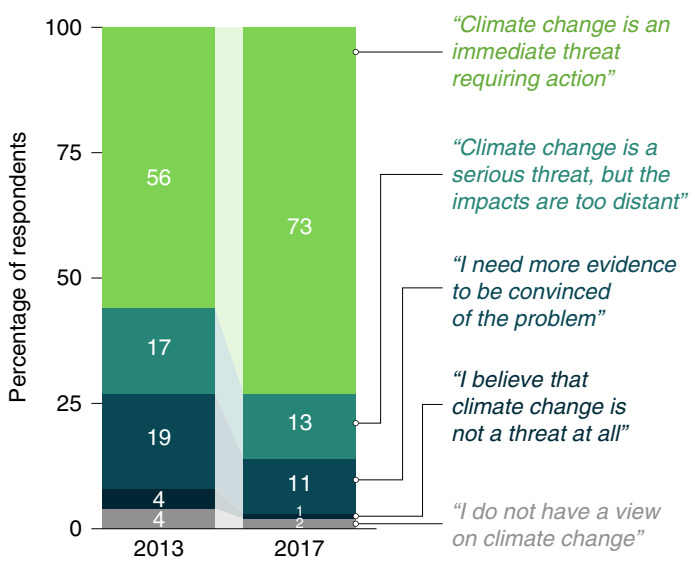

Fig. 2 | Changes in perceived threats to the GBR and in climate change attitudes. a, The percentages of tourists in $2013(n=2,877)$ and $2017(n=1,804)$ who identified specific threats among their perceived "three most serious threats to the GBR". The top 12 response themes are shown for each group. b. The percentages of tourists in $2013(n=2,877)$ and $2017(n=1,804)$ choosing each of five statements to represent their awareness and attitude towards climate change.

visible and identifiable at tourist sites, thus influencing visitors' wider threat perceptions ${ }^{51}$. While tourism has not been recognized in any recent scientific literature as among the most serious threats to the GBR, our results suggest that in 2013 many GBR tourists were probably unaware of the level of risk associated with other, scientifically recognized, threats such as climate change; and that any effects that could be attributed to such threats were less (or were not) visible to GBR tourists at that time.

There was a marked increase from 2013 to 2017 in the proportion of tourists who reported their acceptance that "climate change is an 
immediate threat requiring action" (56 to $73 \%$; Fig. 2 b). While this proportion for international tourists (increasing from 64\% in 2013 to $78 \%$ in 2017) was higher than that for Australians (increasing from $50 \%$ in 2013 to $67 \%$ in 2017), the magnitude of this increase in both groups towards recognition of the climate change threat, its immediacy and the need for action, represents a substantial shift in normative attitudes toward climate change at a scale and in a timeframe not reported in previous studies. Previous annual surveys of Australian attitudes towards climate change, over the period from 2010 to 2014, showed that while the attitudes of individuals fluctuated, the aggregate levels of opinion remained stable over that time $^{52}$. Whether the observed changes in 2017 represent a reaction at a moment in time or a lasting change in attitudes is uncertain and further work is needed to determine whether these perceptions have become normalized in the wider population.

While we cannot conclusively attribute the cause of this attitudinal change to the GBR coral bleaching events, we believe that a strong influence and 'risk amplification' was likely, considering the scale of the event, its extensive media coverage that explicitly attributed the events to climate change ${ }^{37}$, associated imagery, as well as the direct observation of affected reef sites by many tourists who visited the GBR over this time. While the more sensationalized and fatalistic media stories of the coral bleaching events and the GBR's imperilled status have been criticized for their potential to cause public disengagement and a loss of hope in mitigation actions $s^{37}$, the broader exchange of information precipitated by this risk event may have had positive outcomes on public threat awareness (Fig. 2a) and support for mitigative action (Fig. 2b).

\section{Personal experience and perceptions}

We found significant declines in tourists' perceptions of the GBR's aesthetic beauty, their overall satisfaction with their experience of the GBR (among those who had visited) and in their ratings of the quality of reef tourism activities (among those who had participated; Table 1a). While the 2017 mean scores remained relatively high on a 10-point scale (ranging between 7.46 and 8.52), there is an inherent positivity bias associated with tourist satisfaction ratings and relatively small changes can signal a qualitative distinction ${ }^{53}$.

The aesthetic appreciation of natural settings is a fundamental way in which people relate to the environment, and aesthetic perceptions play a critical role in the satisfaction that tourists derive from places $^{54}$. In a coral reef setting, physical attributes that have been correlated quantitatively with non-expert ratings of aesthetic beauty include water clarity, fish abundance and 'coral topography' (the complexity of coral formations and features); however, many more visual and sensory attributes contribute to people's overall aesthetic appraisal ${ }^{54}$. Imagery associated with the mass coral bleaching events was widely featured in media articles, in which aerial and underwater scenes of white, pale and fluorescent corals were often depicted (for example, see the March 2017 cover of Nature ${ }^{55}$ ). Such imagery is visually striking, and scenes of bleached coral gardens can even be considered beautiful ${ }^{56}$. Such scenes are typically shortlived: once mortality occurs, brown algae quickly smothers coral skeletons ${ }^{57}$. While the biological process of coral bleaching is complex and its explanation is technical, the imagery from the event may have been highly engaging to non-expert audiences, overcoming barriers that have been associated with 'expert' conceptualizations of climate change threats and impacts ${ }^{18}$.

At the time of the 2017 tourist survey (July-August), bleached coral was still present in low levels; however, mortality associated with the 2016 coral bleaching event had already occurred from Cairns to the far north of the GBR, and cyclone-damaged reefs and islands in the Whitsundays region had not recovered ${ }^{58}$. We therefore consider that a substantial proportion of the 1,076 respondents who had visited the GBR when surveyed in 2017 probably had personally experienced and observed affected areas, influencing their aesthetic perceptions and satisfaction. However, as noted above, the personal observation of impacts on the GBR was not a requisite for recalling a negative emotional response to the GBR (Fig. 1c).

\section{Effects on place values, pride and identity}

Understanding place values, which represent the estimated worth and meaning of a place, is important for environmental management and decision making ${ }^{59,60}$. We found that strong, shared values for an icon are responsive to ecosystem disturbances and threats. In contrast with the declines in ratings of GBR perceptions and the tourist experience reported above, we found small but significant increases from 2013 to 2017 in ratings of values attributed to the GBR, including its biodiversity value, scientific and education value, lifestyle value and international icon value. Similarly, pride and identity associated with the GBR were significantly higher in 2017 (Table 1b). Pride in the GBR and GBR identity were positively correlated with these cultural values attributed to the GBR (see Table 2). Place values, such as those recorded for the GBR's biodiversity, scientific heritage and lifestyle values, are consistently strong among diverse stakeholder groups (geographically proximate and distal alike), whereas greater variability is expressed for pride and identity ${ }^{27}$, consistent with the lower mean scores for GBR identity among tourists (Table $1 \mathrm{~b}$ ).

We propose that these increased ratings for (or expressions of) place values, identity and pride are complementary to the expression of ecological grief (representing 'ecological empathy'), and form part of the holistic affective response to an imperilled climate icon. Empathy for nature stems from a recognition of its intrinsic value and a feeling of connectedness to it (for example, pride and identity ${ }^{61}$ and the desire to protect the environment has been proposed as an extension of Maslow's 'values of being' in the self-actualization process ${ }^{61}$. Knowing that such values can change in response to environmental change highlights a need for their continued assessment. As loss and ecological grief are expected to become increasingly common responses to climate impacts ${ }^{21,41}$, the health literature on cumulative trauma suggests that 'compassion fatigue' ${ }^{62}$ and the erosion of ecological empathy (or 'environmental numbness') ${ }^{63}$ may occur.

\section{Protective sentiment and self-efficacy}

While protective sentiment associated with the GBR increased significantly in 2017, including tourists' willingness to act and willingness to learn (Table 1c), there was a corresponding decline in self-efficacy, represented here by capacity to act and optimism for the future of the GBR. The slight increase in ratings for sense of agency and opportunity to act indicates some self-awareness of the individual's role in mitigating threats. However, the corresponding decline in sense of individual responsibility suggests that community expectations of responsibility and capacity for addressing great threats such as climate change are located in the actions of governments and corporations, rather than their own actions.

\section{Conclusions}

Our study identified a clear affective response amongst tourists, whose protective sentiment for the GBR became heightened after a notable climate impact, while their sense of self-efficacy diminished. Concomitant with grief-associated emotive responses (sadness, anger and fear; Fig. 1c), respondents expressed empathy for the icon through increased ratings of place values, identity and protective sentiment (Table 1a,b).

While our study is limited to tourists, we note that they represent diverse national and international stakeholder interests, attitudes and values, from widespread places of origin. Their affective responses in this case were not dependent on visits to the GBR and personal experience of impacts (Fig. 1c), indicating other contributing influences; for example, sensationalized media representations ${ }^{37}$ 
Table 1 | Changes to the tourist experience and GBR perceptions, place values and protective sentiments

\begin{tabular}{|c|c|c|c|c|}
\hline & $\begin{array}{l}\text { 2013: mean } \\
( \pm \text { s.e.m. })\end{array}$ & $\begin{array}{l}\text { 2017: mean } \\
( \pm \text { s.e.m. })\end{array}$ & $\begin{array}{l}\text { Test statistic }(U) \text {; } \\
\text { effect size }(r)\end{array}$ & $\begin{array}{l}\text { Direction of c } \\
\text { significance ( }\end{array}$ \\
\hline \multicolumn{5}{|c|}{ (a) Quality of tourist experience and perceptions of the GBR (ratings of agreement, quality, satisfaction; $1-10$ scale, $1=$ lowest, $10=$ highest } \\
\hline $\begin{array}{l}\text { "The aesthetic beauty of the GBR is outstanding" (aesthetic } \\
\text { perception) (GBR visitor subset; } 2013 n=1,951 ; 2017 n=1,076 \text { ) }\end{array}$ & $8.94( \pm 0.033)$ & $8.52( \pm 0.056)$ & $\begin{array}{l}U=929,910.5 \\
r=-0.10\end{array}$ & $\downarrow P=0.000$ \\
\hline $\begin{array}{l}\text { Quality of snorkelling (participant subset; } 2013 n=1,041 ; 2017 \\
n=699 \text { ) }\end{array}$ & $8.18( \pm 0.05$ & $7.46( \pm 0.083)$ & $\begin{array}{l}U=297,981.0 \\
r=-0.16\end{array}$ & 00 \\
\hline $\begin{array}{l}\text { Quality of scuba diving (participant subset; } 2013 n=364 ; 2017 \\
n=275 \text { ) }\end{array}$ & $8.30( \pm 0.095)$ & $7.49( \pm 0.148)$ & $\begin{array}{l}U=40,625.0 \\
r=-0.16\end{array}$ & $\downarrow P=0.000$ \\
\hline $\begin{array}{l}\text { Quality of wildlife watching (participant subset; } 2013 n=962 \text {; } \\
2017 n=515 \text { ) }\end{array}$ & $8.50( \pm 0.048)$ & $7.97( \pm 0.084)$ & $\begin{array}{l}U=210,593.5 \\
r=-0.13\end{array}$ & $\downarrow P=0.000$ \\
\hline $\begin{array}{l}\text { Overall satisfaction with this experience of the GBR (GBR visitor } \\
\text { subset; } 2013 n=2015 ; 2017 n=1,073 \text { ) }\end{array}$ & $8.46( \pm 0.031)$ & $8.07( \pm 0.053)$ & $\begin{array}{l}U=952,631.0 \\
r=-0.10\end{array}$ & $\downarrow P=0.000$ \\
\hline
\end{tabular}

(b) Place values, pride and identity associated with the GBR (ratings of agreement: $1=$ very strongly disagree, $10=$ very strongly agree)

\begin{tabular}{|c|c|c|c|c|}
\hline $\begin{array}{l}\text { "I value the GBR because it supports a variety of life, such as } \\
\text { fish and corals" (biodiversity value) }\end{array}$ & $8.98( \pm 0.027)$ & $9.21( \pm 0.032)$ & $\begin{array}{l}U=2,222,887.0 \\
r=-0.10\end{array}$ & $\uparrow P=0.000$ \\
\hline $\begin{array}{l}\text { "I value the GBR because we can learn about the environment } \\
\text { through scientific discoveries" (scientific heritage value) }\end{array}$ & $8.29( \pm 0.036)$ & $8.69( \pm 0.040)$ & $\begin{array}{l}U=2,138,690.0 \\
r=-0.11\end{array}$ & $\uparrow P=0.000$ \\
\hline $\begin{array}{l}\text { "I value the GBR because it supports a desirable and active way } \\
\text { of life" (lifestyle value) }\end{array}$ & $8.04( \pm 0.037)$ & $8.28( \pm 0.047)$ & $\begin{array}{l}U=2,229,313.5 \\
r=-0.08\end{array}$ & $\uparrow P=0.000$ \\
\hline $\begin{array}{l}\text { "I value the GBR because it attracts people from all over the } \\
\text { world" (international icon value) }\end{array}$ & $7.79( \pm 0.044)$ & $8.24( \pm 0.056)$ & $\begin{array}{l}U=2,105,251.5 \\
r=-0.12\end{array}$ & $\uparrow P=0.000$ \\
\hline $\begin{array}{l}\text { "I feel proud that the GBR is a World Heritage Area" (pride in } \\
\text { the GBR) }\end{array}$ & $8.77( \pm 0.034)$ & $8.99( \pm 0.039)$ & $\begin{array}{l}U=2,236,301.0 \\
r=-0.08\end{array}$ & $\uparrow P=0.000$ \\
\hline "The GBR is part of my identity" (GBR identity) & $4.63( \pm 0.058)$ & $4.82( \pm 0.070)$ & $\begin{array}{l}U=2,111,818.0 \\
r=-0.03\end{array}$ & $\uparrow P=0.041$ \\
\hline
\end{tabular}

(c) Protective sentiment and self-efficacy (ratings of agreement: $1=$ very strongly disagree, $10=$ very strongly agree) to act)

"I would like to learn more about the condition of the GBR" (willingness to learn)

"I do not have the time or opportunity required to reduce any impact that I might have on the GBR" (opportunity to act)a

$7.02( \pm 0.042)$

$6.81( \pm 0.044)$

$4.69( \pm 0.053)$

$4.96(+0.059)$

$4.98( \pm 0.052)$

$5.20( \pm 0.061)$

the GBR" (sense of agency)

"It is my responsibility to protect the GBR" (sense of individual responsibility) ${ }^{a}$

"I have the necessary knowledge and skills to reduce any impact that I might have on the GBR" (capacity to act)

"I feel optimistic about the future of the GBR" (optimism)
$6.43( \pm 0.050) \quad 6.33( \pm 0.058)$

$5.28( \pm 0.051) \quad 4.55( \pm 0.058)$

$6.18( \pm 0.047)$

$\begin{array}{ll}U=2,141,775.5 & \uparrow P=0.000 \\ r=-0.09 & \\ U=2,148,977.5 & \uparrow P=0.000 \\ r=-0.11 & \\ U=2,190,395.0 & \uparrow P=0.004 \\ r=-0.04 & \\ U=2,258,414.0 & \uparrow P=0.021 \\ r=-0.03 & \\ U=2,305,122.5 & \downarrow P=0.009 \\ r=-0.04 & \\ U=1,991,622.5 & \downarrow P=0.000 \\ r=-0.14 & \\ U=1,992,016.0 & \downarrow P=0.000 \\ r=-0.14 & \end{array}$

aStatements were worded negatively in the survey to reduce systematic bias in responses; rating scores are inverted to show equivalent for positive wording. a-c, Comparison of mean ratings (2013 $n=2,877$ and $2017 n=1,804$; \pm s.e.m.) and statistical test results (Mann-Whitney U-test; 95\% confidence interval) for tourists in the GBR region, comparing indicators of quality of the tourist experience and perception of the GBR (includes subsets of respondents who had visited the GBR and participated in those activities) (a), place values, pride and identity associated with the GBR (b) and protective sentiment, self-efficacy and optimism (c).

and imagery of the coral bleaching event. This suggests that representations of icons like the GBR, when subject to a high-profile risk event, can elicit wide-reaching affective responses, amplify risks and proximize the climate change issue. However, like other examples of the iconic approach for representing climate change, the observed decline in self-efficacy represents a barrier to productive engagement in mitigative actions. In particular, the expression of fear (Fig. 1c) and the observed decline in individual sense of responsibility (Table 1c) may be indicative of the perceived scale of the climate threat and the intractability of the problem through individual efforts alone. Nonetheless, the expressions of protective sentiment in this context suggest a significant potential to mobilize public support around addressing threats to icons, like the GBR, where opportunities for individual action are linked to a broader, collective response.

From an action perspective, our findings can be considered both potentially constraining (due to reduced self-efficacy) and enabling (due to increased protective sentiment). Management, scientific or conservation agencies that seek to engage communities in climate mitigation and adaptation may arouse high levels of interest and empathy by using evocative imagery of icons during crises or high-profile events. However, achieving and sustaining engagement in collective action will require a more strategic and thoughtful approach to overcome efficacy barriers. Prevailing over such barriers can potentially be achieved by drawing on lessons from health and psychology literature, including, for example, the 
Table 2 | Correlations between GBR place values, pride and identity

\begin{tabular}{|c|c|c|c|c|}
\hline & \multicolumn{2}{|c|}{$\begin{array}{l}\text { (a) "I feel proud that the GBR } \\
\text { is a World Heritage Area" } \\
\text { (pride in the GBR) }\end{array}$} & \multicolumn{2}{|c|}{$\begin{array}{l}\text { (b) "The GBR is part of my } \\
\text { identity" (GBR identity) }\end{array}$} \\
\hline & $\begin{array}{l}\text { Correlation } \\
\text { coefficient }(r)\end{array}$ & $\begin{array}{l}\text { Significance } \\
\text { (two-tailed) }\end{array}$ & $\begin{array}{l}\text { Correlation } \\
\text { coefficient }(r)\end{array}$ & $\begin{array}{l}\text { Significance } \\
\text { (two-tailed) }\end{array}$ \\
\hline $\begin{array}{l}\text { "I value the GBR because it supports a variety of life, such as fish and corals" } \\
\text { (biodiversity value) }\end{array}$ & 0.550 & $P=0.000$ & 0.210 & $P=0.000$ \\
\hline $\begin{array}{l}\text { "I value the GBR because we can learn about the environment through scientific } \\
\text { discoveries" (scientific heritage value) }\end{array}$ & 0.477 & $P=0.000$ & 0.256 & $P=0.000$ \\
\hline $\begin{array}{l}\text { "I value the GBR because it supports a desirable and active way of life" } \\
\text { (lifestyle value) }\end{array}$ & 0.429 & $P=0.000$ & 0.304 & $P=0.000$ \\
\hline $\begin{array}{l}\text { "I value the GBR because it attracts people from all over the world" (international } \\
\text { icon value) }\end{array}$ & 0.372 & $P=0.000$ & 0.259 & $P=0.000$ \\
\hline
\end{tabular}

a,b, Spearman's rho correlations $(n=4,681)$ between ratings for place values: pride in the GBR (a) and identity associated with the GBR (b).

'small changes' approach ${ }^{64}$, positive affirmation and promotion of incremental successes ${ }^{65}$, and fostering pride in pro-environmental behaviours ${ }^{66}$. Maintaining hope, balanced with clear and accessible actions linked to attainable goals, also remains critical to motivating people and sustaining their engagement in collective efforts to restore, mitigate and adapt ${ }^{63,67}$.

Engaging with loss and grief represents an additional challenge that requires sensitivity. An understanding of shared place values provides an important basis for constructive engagement with the possibility of loss, and appealing to such values can empower communities and motivate cooperation to offset potentially harmful outcomes $^{21,22}$. However, it is important to recognize that wider place values are heterogeneous, that some may be in conflict, and that respectful, transparent dialogue provides the best avenue to negotiate areas of contention ${ }^{68}$.

Our study provides insights into some of the shared place values assigned to the GBR among one, albeit diverse, non-local stakeholder group. As a multiple-use marine park and World Heritage area, with adjacent coastal communities dependent on tourism, fishing, agriculture and mining (among other industries), and with cross-scale communities deriving wellbeing from a broad range of cultural and ecosystem services, the GBR represents an important example among climate icons that encapsulates a multiplex of human values that are challenged by climate change. Like other natural World Heritage-listed sites, the full extent of cultural and other intangible values that are at stake in the GBR remains poorly understood ${ }^{31}$. Research to describe the diversity and importance of human values associated with iconic places that are vulnerable to loss is needed, as a precursor to predicting how such values might respond to future losses, to guide coordinated responses to the climate threat and to mitigate potential suffering from future impacts ${ }^{21,22}$.

\section{Online content}

Any methods, additional references, Nature Research reporting summaries, source data, statements of code and data availability and associated accession codes are available at https://doi.org/10.1038/ s41558-019-0504-y.

Received: 11 December 2018; Accepted: 10 May 2019;

Published online: 24 June 2019

\section{References}

1. Lee, T. M., Markowitz, E. M., Howe, P. D., Ko, C. \& Leiserowitz, A. A. Predictors of public climate change awareness and risk perception around the world. Nat. Clim. Change 5, 1014-1020 (2015).

2. Lacey, J., Howden, M., Cvitanovic, C. \& Colvin, R. M. Understanding and managing trust at the climate science-policy interface. Nat. Clim. Change $\mathbf{8}$ 22-28 (2018).
3. Lorenzoni, I., Nicholson-Cole, S. \& Whitmarsh, L. Barriers perceived to engaging with climate change among the UK public and their policy implications. Glob. Environ. Change 17, 445-459 (2007).

4. Rogelj, J., McCollum, D. L., Reisinger, A., Meinshausen, M. \& Riahi, K. Probabilistic cost estimates for climate change mitigation. Nature 493 , 79-83 (2013).

5. van der Linden, S. L. The social-psychological determinants of climate change risk perceptions: towards a comprehensive model. J. Environ. Psychol. 41, 112-124 (2015).

6. van der Linden, S. L., Leiserowitz, A. A., Feinberg, G. D. \& Maibach, E. W. The scientific consensus on climate change as a gateway belief: experimental evidence. PLoS ONE 10, e0118489 (2015).

7. Wynne, B. Creating public alienation: expert cultures of risk and ethics on GMOs. Sci. Cult. 10, 445-481 (2001).

8. Wood, W. Attitude change: persuasion and social influence. Annu. Rev. Psychol. 51, 539-570 (2000).

9. O’Neill, S., Boykoff, M., Neimeyer, S. \& Day, S. A. On the use of imagery for climate change engagement. Glob. Environ. Change 23, 413-421 (2013).

10. Ockwell, D., Whitmarsh, L. \& O'Neill, S. Reorienting climate change communication for effective mitigation: forcing people to be green or fostering grass-roots engagement? Sci. Commun. 30, 305-327 (2009).

11. Myers, T. A., Maibach, E. W., Roser-Renouf, C., Akerlof, K. \& Leiserowitz, A. A. The relationship between personal experience and belief in the reality of global warming. Nat. Clim. Change 3, 343-347 (2013).

12. Singh, A. S., Zwickle, A., Bruskotter, J. T. \& Wilson, R. The perceived psychological distance of climate change impacts and its influence on support for adaptation policy. Environ. Sci. Policy 73, 93-99 (2017).

13. Scannell, L. \& Gifford, R. Personally relevant climate change: the role of place attachment and local versus global message framing in engagement. Environ. Behav. 45, 60-85 (2013).

14. Smith, N. \& Leiserowitz, A. The role of emotion in global warming policy support and opposition. Risk Anal. 34, 937-948 (2014).

15. Skurka, C., Niederdeppe, J., Romero-Canyas, R. \& Acup, D. Pathways of influence in emotional appeals: benefits and tradeoffs of using fear or humor to promote climate change-related intentions and risk perceptions. J. Commun. 68, 169-193 (2018).

16. Milne, S., Sheeran, P. \& Orbell, S. Prediction and intervention in healthrelated behaviour: a meta-analytic review of protection motivation theory. J. Appl. Soc. Psychol. 30, 106-143 (2000).

17. O’Neill, S. \& Nicholson-Cole, S. "Fear Won't Do It": promoting positive engagement with climate change through visual and iconic representations. Sci. Commun. 30, 355-379 (2009).

18. O'Neill, S. J. \& Hulme, M. An iconic approach for representing climate change. Glob. Environ. Change 19, 402-410 (2009).

19. Höijer, B. Emotional anchoring and objectification in the media reporting on climate change. Public Underst. Sci. 19, 717-731 (2010).

20. Edensor, T. National Identity, Popular Culture and Everyday Life (Bloomsbury, 2002).

21. Barnett, J., Tschakert, P., Head, L. \& Adger, W. N. A science of loss. Nat. Clim. Change 6, 976-978 (2016).

22. Tschakert, P. et al. Climate change and loss, as if people mattered: values, places, and experiences. WIREs Clim. Change 8, e476 (2017).

23. Dow, K. et al. Limits to adaptation. Nat. Clim. Change 3, 305-307 (2013).

24. Goldberg, J. et al. Climate Change, the Great Barrier Reef and the response of Australians. Palgrave Commun. 2, 15046 (2016). 
25. Marshall, N. A. et al. The dependency of people on the Great Garrier Reef, Australia. Coast. Manag. 45, 505-518 (2017).

26. Gurney, G. G. et al. Redefining community based on place attachment in a connected world. Proc. Natl Acad. Sci. USA 114, 10077-10082 (2017)

27. Marshall, N. et al. Measuring what matters in the Great Barrier Reef. Front. Ecol. Environ. 16, 271-277 (2018).

28. Coghlan, A. Linking natural resource management to tourist satisfaction: a study of Australia's Great Barrier Reef. J. Sustain. Tour. 20, 41-58 (2012).

29. Esparon, M., Stoeckl, N., Farr, M. \& Larson, S. The significance of environmental values for destination competitiveness and sustainable tourism strategy making: insights from Australia's Great Barrier Reef World Heritage Area. J. Sustain. Tour. 23, 706-725 (2015)

30. At What Price? The Economic, Social and Icon Value of the Great Barrier Reef (Great Barrier Reef Foundation, 2017).

31. Great Barrier Reef Outlook Report 2014 (Great Barrier Reef Marine Park Authority, 2014).

32. Final Report: 2016 Coral Bleaching Event on the Great Barrier Reef (Great Barrier Reef Marine Park Authority, 2017).

33. James, L. E. Half the Great Barrier Reef is dead. National Geographic Magazine (August 2018); https://www.nationalgeographic.com/ magazine/2018/08/explore-atlas-great-barrier-reef-coral-bleaching-mapclimate-change/

34. Reef Health (Great Barrier Reef Marine Park Authority, 2019); http://www.gbrmpa.gov.au/the-reef/reef-health

35. Chen, D. Cyclone Debbie leaves Whitsunday Islands reefs in ruins. ABC News (9 April 2017); https://www.abc.net.au/news/2017-04-09/cyclone-debbieleaves-whitsundays-reefs-in-ruins/8428866

36. Heron, S. F. et al. Impacts of Climate Change on World Heritage Coral Reefs: A First Scientific Assessment (UNESCO World Heritage Centre, 2017); https://whc.unesco.org/en/news/1676/

37. Eagle, L., Hay, R. \& Low, D. R. Competing and conflicting messages via online new media: potential impacts of claims that the Great Barrier Reef is dying. Ocean Coast. Manag. 158, 154-163 (2018).

38. Willacy, M. Great Barrier Reef coral bleaching could cost $\$ 1 \mathrm{~b}$ in lost tourism, research suggests. $A B C$ News (21 June 2016); https://www.abc.net.au/ news/2016-06-21/reef-bleaching-could-cost-billion-in-lost-tourism/7526166

39. Annual Report 2017-2018 (Great Barrier Reef Marine Park Authority, 2018)

40. Piggott-McKellar, A. E. \& McNamara, K. E. Last chance tourism and the Great Barrier Reef. J. Sustain. Tour. 25, 397-415 (2016).

41. Cunsolo, A. \& Ellis, N. R. Ecological grief as a mental health response to climate change-related loss. Nat. Clim. Change 8, 275-281 (2018).

42. Archer, J. The Nature of Grief (Routledge, 1999).

43. Smith, K. B., Oxley, D., Hibbing, M. V., Alford, J. R. \& Hibbin, J. R. Disgust sensitivity and the neurophysiology of left-right political orientations. PLoS ONE 6, e25552 (2011).

44. Head, L. The Anthropoceneans. Geogr. Res. 53, 313-320 (2015).

45. Adger, W. N., Barnett, J., Brown, K., Marshall, N. \& O’Brien, K. Cultural dimensions of climate change impacts and adaptation. Nat. Clim. Change 3, 112-117 (2013).

46. Marshall, N. et al. Reef grief: investigating the relationship between place meanings and place change on the Great Barrier Reef, Australia. Sustain. Sci. 14, 579-587 (2019).

47. Kasperson, R. E. et al. The social amplification of risk: a conceptual framework. Risk Anal. 8, 177-187 (1988).

48. Kasperson, J. X., Kasperson, R. E., Pidgeon, N. \& Slovic, P. in The Social Amplification of Risk (eds Pidgeon, N. et al.) Ch. 1 (Cambridge University Press, 2003).

49. Lankester, A. J., Bohensky, E. \& Newlands, M. Media representations of risk: the reporting of dredge spoil disposal in the Great Barrier Reef Marine Park at Abbot Point. Mar. Policy 60, 149-161 (2015).

50. Prideaux, B., McNamara, K. E. \& Thompson, M. The irony of tourism: visitor reflections of their impacts on Australia's World Heritage rainforest. J. Ecotourism 11, 102-117 (2012).

51. Hillery, M., Nancarrow, B., Griffin, G. \& Syme, G. Tourist perception of environmental impact. Ann. Tour. Res. 28, 853-867 (2001).

52. Leviston, Z., Greenhill, M. \& Walker, I. Australian Attitudes to Climate Change and Adaptation: 2010-2014 (CSIRO, 2015).

53. Pearce, P. L. in Managing Tourism and Hospitality Services: Theory and International Applications (eds Prideaux, B. et al.) Ch. 25 (CABI, 2006).
54. Marshall, N. et al. Identifying indicators of aesthetics in the Great Barrier Reef for the purposes of management. PLoS ONE 14, e0210196 (2019).

55. Nature 543, 7645 (2017).

56. Pocock, C. Sense matters: aesthetic values of the Great Barrier Reef. Int. J. Herit. Stud. 8, 365-381 (2002).

57. Brown, B. E. Coral bleaching: causes and consequences. Coral Reefs 16, S129-S138 (1997).

58. Hughes, T. P. et al. Global warming transforms coral reef assemblages. Nature 556, 492-496 (2018).

59. Ives, C. D. \& Kendal, D. The role of social values in the management of ecological systems. J. Environ. Manag. 144, 67-72 (2014).

60 . Kenter, J. O. et al. What are shared and social values of ecosystems? Ecol. Econ. 111, 86-99 (2015).

61. Kuhn, J. L. Toward and ecological humanistic psychology. J. Humanist. Psychol. 41, 9-24 (2001).

62. Figley, C. R. (ed.) Compassion Fatigue: Coping with Secondary Traumatic Stress Disorder in Those Who Treat the Traumatized (Routledge, 1995).

63. Gifford, R. The dragons of inaction: psychological barriers that limit climate change mitigation and adaptation. Am. Psychol. 66, 290-302 (2011).

64. Hill, J. O., Wyatt, H. R., Reed, G. W. \& Peters, J. C. Obesity and the environment: where do we go from here? Science 299, 853-855 (2003).

65. Epton, T. \& Harris, P. R. Self-affirmation promotes health behaviour change. Health Psychol. 27, 746-752 (2008).

66. Harth, N. S., Leach, C. W. \& Kessler, T. Guilt, anger, and pride about in-group environmental behaviour: different emotions predict distinct intentions. J. Environ. Psychol. 34, 18-26 (2013).

67. Hobbs, R. J. Grieving for the past and hoping for the future: balancing polarizing perspectives in conservation and restoration. Restor. Ecol. 21 145-148 (2013)

68. Chapin, F. S. \& Knapp, C. N. Sense of place: a process for identifying and negotiating potentially contested visions of sustainability. Environ. Sci. Policy 53, 38-46 (2015).

\section{Acknowledgements}

This study was conducted using data from the Social and Economic Long-Term Monitoring Program for the Great Barrier Reef (SELTMP: https://research.csiro.au/ seltmp/) with funding provided by the Australian and Queensland Governments as part of the Reef 2050 Integrated Monitoring and Reporting Program (2017-2019) and the Australian Government's National Environmental Research Program, Tropical Ecosystems Hub (2011-2015). S.F.H. was supported by National Oceanic and Atmospheric (NOAA) grant (no. NA14NES4320003) (Cooperative Institute for Climate and Satellites) at the University of Maryland/ESSIC. The scientific results and conclusions, as well as any views or opinions expressed herein, are those of the authors and do not necessarily reflect the views of the Australian Government, the Minister for the Environment, the Queensland Government, NOAA or the US Department of Commerce.

\section{Author contributions}

N.A.M., M.I.C., P.L.P., J.G. and others designed the research and collected data. M.I.C. L.T., G.W. and N.A.M. analysed the data. M.I.C., N.A.M., L.T., S.F.H., J.H., B.T., P.L.P. and J.G. wrote the paper.

\section{Competing interests}

The authors declare no competing interests.

\section{Additional information}

Supplementary information is available for this paper at https://doi.org/10.1038/ s41558-019-0504-y.

Reprints and permissions information is available at www.nature.com/reprints. Correspondence and requests for materials should be addressed to M.I.C.

Peer review information: Nature Climate Change thanks Karen McNamara, Nick Pidgeon and other, anonymous, reviewer(s) for their contribution to the peer review of this work.

Publisher's note: Springer Nature remains neutral with regard to jurisdictional claims in published maps and institutional affiliations.

(c) Crown 2019 


\section{Methods}

Survey design. To measure and compare tourists' perceptions and values of the GBR and protective sentiments for the GBR, we used a series of statements from an established framework for monitoring human-environment cultural and place values ${ }^{27}$ and asked survey respondents to indicate their level of agreement/ disagreement on a 10 -point scale ( $1=$ very strongly disagree; $10=$ very strongly agree) Similarly, we asked respondents who had visited the GBR to provide ratings of their satisfaction ( $1=$ extremely dissatisfied; $10=$ extremely satisfied $)$ and the quality of popular reef-based activities ( $1=$ very low quality; $10=$ very high quality) if they had undertaken them during their visit. Climate change threat awareness and perceptions were elicited by asking respondents to select one statement from five options that best reflected their viewpoint: (1) "climate change is an immediate threat requiring action", (2) "climate change is a serious threat but the impacts are too distant for immediate concern", (3) "I need more evidence to be convinced of the problem", (4) "I believe that climate change is not a threat at all" and (5) "I do not have a view on climate change". To elicit threat perceptions, respondents were asked to list what they thought were the "three most serious threats to the GBR" in a short, open-ended format. While some minor changes were made to the overall survey instrument between 2013 and 2017, the questions used for our analyses in this study remained identical.

Data collection. Tourists in the GBR region (defined as the GBR catchment, bounded by Cape York in the north, Bundaberg in the south and the Great Dividing Range in the west) were surveyed using face-to-face interviews between June and August in both 2013 and 2017 (ref. ${ }^{69}$ ). For the purposes of this study we defined tourists broadly as non-resident visitors to the GBR region. The surveys were conducted at 14 regional population centres along the coast, in public locations such as beaches, boat ramps, parks, shopping centres and markets, and on a limited number of GBR tourism vessels. Interviews were conducted by trained survey staff, and responses were entered in situ into tablet computers, using the iSurvey application. In 2013, we achieved a sample of 2,877 tourists $(1,557$ of whom were Australian, 1,286 from overseas and 34 respondents who did not provide their place of origin), followed by a sample of 1,804 tourists in 2017 (831 Australian, 805 from overseas and 168 respondents who did not provide their place of origin). Our sampling strategy used a combination of convenience and quota sampling ${ }^{70}$, to minimize potential biases for gender, age and nationality. However, a limitation of the study was its availability in English only, and we acknowledge that some non-English-speaking tourist market segments are under-represented (for example, tourists from China). This research involving human participants was reviewed and approved by the CSIRO Social Science Human Research Ethics Committee and was conducted in accordance with the Australian National Statement on Ethical Conduct in Human Research (2007). All respondents gave informed consent to participate in the voluntary survey.

Description of sample. The demography and location of origin for both domestic and international tourists was comparable between years; however, in 2017, the mean age of domestic tourists was lower than that for $2013(43.5 \pm 0.45 \mathrm{yr}$ compared with $48.9 \pm 0.64 \mathrm{yr}$ respectively). A higher proportion of females was represented among the international tourists in both years (55\% of our sample in 2013 and 57\% in 2017). Overseas respondents came from 54 countries in our 2013 sample and 35 countries in our 2017 sample. Most international respondents came from Europe and North America, with the largest proportions originating from the United Kingdom (25\% in 2013 and 19\% in 2017), Germany (18\% in 2013 and 19\% in 2017), France (12\% in 2013 and $11 \%$ in 2017) and the United States ( $8 \%$ in 2013 and $11 \%$ in 2017). Most domestic tourists were repeat visitors to the GBR region (77\% in both years), while most international tourists were first-time visitors to the region (84\% in 2013 and $86 \%$ in 2017). Among domestic tourists, 58\% in both years had visited the GBR during their stay in the region; among international tourists, $85 \%$ had visited the GBR in 2013 and $67 \%$ had visited the GBR in 2017 . The number of responses $(n)$ varied for some of the survey questions (for example, ratings of the quality of scuba diving, snorkelling and wildlife watching were limited to respondents who had participated in those activities); where relevant, these differing sample sizes are shown (Table 1), with accompanying standard errors for mean scores.

Statistical analyses of numeric data. We used MS Excel and SPSS (v.22) software for analyses of numeric data (providing means and comparing the distribution of rating scores for a range of 10-point scaled response questions, as described above) Non-parametric Mann-Whitney U-tests (Table 1) and Spearman's rho correlation tests (Table 2) were used, as the appropriate statistical tools for ordinal (10-point rating scale) data ${ }^{71}$. Effect sizes $(r)$ were calculated manually from the SPSS output $z$ value using: $r=\frac{z}{\sqrt{n}}$

Word-emotion analysis and word clouds. Our first question in the survey asked, in an open-ended short response format: "what are the first words that come to mind when you think about the GBR?" Responses were cleaned (correcting spelling, removing punctuation and stop words) and their association with eight core emotions theorized by R. Plutchik (fear, anger, joy, sadness, trust, disgust, anticipation and surprise $)^{72}$ were scored on a binary scale $(0=$ not associated, $1=$ associated) using the National Research Council of Canada Word-Emotion Association Lexicon $(\text { EmoLex })^{73}$. EmoLex is a large, high-quality, word-emotion lexicon in which more than 14,000 English unigrams (nouns, verbs, adjectives and adverbs) and 25,000 word senses were manually annotated by crowdsourcing ${ }^{74}$, noting that multiple emotions can be evoked simultaneously by the same word. We then calculated, for each emotion, the difference in average occurrence $( \pm 95 \%$ confidence interval) between 2017 and 2013.

To produce the word-cloud visualizations showing basic emotional valence/ sentiment associated with words/terms (positive or negative valence shown in blue and red, respectively; Fig. 1a,b), we adapted EmoLex to account for the contextual relevance of particular words used when referring to a coral reef ecosystem. We removed words that otherwise would have been identified as negatively valenced (for example 'cold', 'sharks' and 'wild') or positively valenced (for example 'hot' and 'warm') outside this context. New words that we categorized as positively valanced included 'diversity', 'life, 'icon', 'pristine', 'heritage', 'colours,' 'relaxing, 'sunshine', 'biggest', 'vast', 'biodiversity', 'natural,' 'nature, 'colourful', 'unique', 'holiday', 'holidays' and 'relax'. New words/terms that we identified as negatively valanced included 'bleaching', 'bleached,' 'climate change', 'coal', 'endangered', 'oil', 'pollution' and 'threatened'. Analyses were done using the $\{\mathrm{tm}\}$ and \{syuzhet $\}$ packages (for text mining and cleaning and for the word-emotion and word cloud/sentiment analyses, respectively) in $\mathrm{R}$

Coding of threats. Respondents were asked "what do you think are the three most serious threats to the GBR" in a short open-ended response format. Ranking of the listed threats by respondents was not taken into account. Responses were cleaned and then sorted into main categories, using MS Excel, with coding checked by at least two researchers. Responses in the pollution category included marine debris, beach litter and a range of other contributors, as well as the generic term 'pollution' The water quality category included agricultural as well as urban and industrial runoff, sediments and pesticides, while coastal development encompassed port developments, dredging and other industrial activities. The fishing category included all extractive activities, commercial and recreational, illegal foreign fishing and 'overfishing' in general. The shipping category included oil spills and ballast water/pollution from shipping. The natural disasters category included responses such as storm damage, cyclones, floods, tsunamis and earthquakes. The climate change category included global warming, rising temperatures (sea and air) and sea level rise. Coral bleaching was coded separately, as was ocean acidification. While climate change, coral bleaching and ocean acidification are related, separate coding of the three terms was considered appropriate. Broad-scale ('mass') coral bleaching events result from heat stress, including the recent GBR events, and have been attributed scientifically to climate change $e^{58,75}$. However, coral bleaching can occur as a result of multiple non-climate change pressures, such as fresh-water inundation and overexposure to direct sunlight ${ }^{57}$. Further to this, heatstress-induced coral bleaching is only one potential effect (or 'symptom') of climate change. Increased storm intensity and/or frequency (physical damage) and sealevel rise (reduced water quality and reef drowning) are other pressures affecting coral reefs that are linked to climate change ${ }^{76}$. Acidification, while associated with climate change as another consequence of increased atmospheric $\mathrm{CO}_{2}$ absorbed by the ocean, is regarded as a separate driver of many (different) pressures affecting marine ecosystems ${ }^{76}$

Reporting Summary. Further information on research design is available in the Nature Research Reporting Summary linked to this article.

\section{Data availability}

The data that support the findings of this study (SELTMP 2013; 2017) ${ }^{69}$ are publicly available from the CSIRO online data access portal at https://doi.org/10.25919/5c74c7a7965dc. The R code used in this study is available from the corresponding author upon reasonable request.

\section{References}

69. Marshall, N., et al. Social and Economic Long Term Monitoring Program (SELTMP) for the Great Barrier Reef Data. v1 (CSIRO, 2019); https://doi.org/1 $0.25919 / 5 \mathrm{c} 74 \mathrm{c} 7 \mathrm{a} 7965 \mathrm{dc}$.

70. Bryman, A. Social Research Methods 4th edn (Oxford Univ. Press, 2012).

71. Fritz, C. O., Morris, P. E. \& Richler, J. J. Effect size estimates: current use, calculations, and interpretation. J. Exp. Psychol. 141, 2-18 (2012).

72. Plutchik, R. A psychoevolutionary theory of emotions. Soc. Sci. Inf. 21, 529-553 (1982).

73. Mohammad, S. M. \& Turney, P. D. Emotions evoked by common words and phrases: using Mechanical Turk to create an emotion lexicon. In Proc. NAACL HLT 2010 Workshop on Computational Approaches to Analysis and Generation of Emotion in Text, 26-34 (Association for Computational Linguistics, 2010).

74. Mohammad, S. M. \& Turney, P. D. Crowdsourcing a word-emotion association lexicon. Comput. Intell. 29, 436-465 (2012).

75. Hughes, T. P. et al. Global warming and recurrent mass bleaching of corals. Nature 543, 373-377 (2017).

76. Spillman, C. M., Heron, S. F., Jury, M. R. \& Anthony, K. R. N. Climate change and carbon threats to coral reefs. Bull. Am. Meteorol. Soc. 92, 1581-1586 (2011). 


\section{Reporting Summary}

Nature Research wishes to improve the reproducibility of the work that we publish. This form provides structure for consistency and transparency in reporting. For further information on Nature Research policies, see Authors \& Referees and the Editorial Policy Checklist.

\section{Statistics}

For all statistical analyses, confirm that the following items are present in the figure legend, table legend, main text, or Methods section.

$\mathrm{n} / \mathrm{a}$ | Confirmed

$\square \bigotimes$ The exact sample size $(n)$ for each experimental group/condition, given as a discrete number and unit of measurement

$\square$ \ A statement on whether measurements were taken from distinct samples or whether the same sample was measured repeatedly

$\square$ The statistical test(s) used AND whether they are one- or two-sided

$\bigotimes$ Only common tests should be described solely by name; describe more complex techniques in the Methods section.

$\square$ \A description of all covariates tested

$\square$ \A description of any assumptions or corrections, such as tests of normality and adjustment for multiple comparisons

$\square$ A full description of the statistical parameters including central tendency (e.g. means) or other basic estimates (e.g. regression coefficient)

AND variation (e.g. standard deviation) or associated estimates of uncertainty (e.g. confidence intervals)

$\square$ For null hypothesis testing, the test statistic (e.g. $F, t, r$ ) with confidence intervals, effect sizes, degrees of freedom and $P$ value noted

$\square$ Give P values as exact values whenever suitable.

Х $\square$ For Bayesian analysis, information on the choice of priors and Markov chain Monte Carlo settings

Х $\square$ For hierarchical and complex designs, identification of the appropriate level for tests and full reporting of outcomes

$\square$ Estimates of effect sizes (e.g. Cohen's $d$, Pearson's $r$ ), indicating how they were calculated

Our web collection on statistics for biologists contains articles on many of the points above.

\section{Software and code}

Policy information about availability of computer code

Data collection Survey data were collected directly from respondents via face to face interviews, with responses entered in situ into tablet computers, using the iSurvey application. No other software or code was used in our data collection.

Data analysis

Statistical analyses of numeric data were performed using MS Excel and SPSS software. Word-emotion analyses of text responses were done using $\mathrm{R}$ and the ssyuzhet package, as described in our methods. The text data and $\mathrm{R}$ code are available from the corresponding author upon reasonable request.

For manuscripts utilizing custom algorithms or software that are central to the research but not yet described in published literature, software must be made available to editors/reviewers. We strongly encourage code deposition in a community repository (e.g. GitHub). See the Nature Research guidelines for submitting code \& software for further information.

\section{Data}

Policy information about availability of data

All manuscripts must include a data availability statement. This statement should provide the following information, where applicable:

- Accession codes, unique identifiers, or web links for publicly available datasets

- A list of figures that have associated raw data

- A description of any restrictions on data availability

Our 2013 and 2017 survey data are publicly available in a persistent repository (CSIRO Data Access Portal): https://doi.org/10.25919/5c74c7a7965dc

Attribution statement: Marshall, N., Curnock, M., Goldberg, J., Gooch, M., Lankester, A., Pert, P., Scherl, L., Stone-Jovicich, S. \& Tobin, R. Social and Economic Long

Term Monitoring Program (SELTMP) for the Great Barrier Reef data. v1. CSIRO. Data Collection. 10.25919/5c74c7a7965dc (2019). 


\section{Field-specific reporting}

Please select the one below that is the best fit for your research. If you are not sure, read the appropriate sections before making your selection.
Life sciences
Behavioural \& social sciences
Ecological, evolutionary \& environmental sciences

For a reference copy of the document with all sections, see nature.com/documents/nr-reporting-summary-flat.pdf

\section{Behavioural \& social sciences study design}

All studies must disclose on these points even when the disclosure is negative.

\section{Study description Quantitative, survey based case study}

Research sample Tourists in the GBR region (defined as the GBR catchment, bounded by Cape York in the north, Bundaberg in the south and the Great Dividing Range in the west) were surveyed via face-to-face interviews between June and August in both 2013 and 2017. For the purposes of this study we defined tourists broadly as non-resident visitors to the GBR region. The surveys were conducted at 14 regional population centres along the coast, in public locations such as beaches, boat ramps, parks, shopping centres, and markets, and on a limited number of GBR tourism vessels. In 2013 we achieved a sample of 2877 tourists (1557 of whom were Australian; 1286 from overseas), followed by a sample of 1804 tourists in 2017 (831 Australian; 805 from overseas). Our sample forms part of the wider data set collected for the Social and Economic Long Term Monitoring Program (SELTMP) for the Great Barrier Reef region, supported by the Australian Government and the Great Barrier Reef Marine Park Authority (further details are available at https://seltmp.eatlas.org.au/ seltmp and https://research.csiro.au/seltmp/).

Sampling strategy Our sampling strategy utilised a combination of convenience and quota sampling (Bryman 2012), to minimise potential biases for gender, age and nationality. However, a limitation of the study was its availability in English only, and we acknowledge that some non-English speaking tourist market segments are under-represented (e.g. tourists from China). No sample size calculation was performed for the tourist data set, due to inherent variability in visitation numbers and patterns. The sample sizes were the maximum achievable within the time and resources available.

Data collection Trained survey staff were deployed to 14 regional population centres along the coast, to conduct face-to-face surveys of respondents in public locations such as beaches, boat ramps, parks, shopping centres, and markets, and on a limited number of GBR tourism vessels. Interviews were conducted by trained survey staff, and responses were entered in situ into tablet computers (iPads), using the iSurvey application.

Timing

Data collection occurred from June to August in 2013, and was replicated from June to August in 2017.

Data exclusions

No data were excluded from the analysis.

Non-participation

Our estimated response rate for SELTMP surveys in 2013 (including both tourists and local residents) was $59 \%$, and in 2017 this response rate was $50 \%$.

Randomization

Participants were not allocated into experimental groups.

\section{Reporting for specific materials, systems and methods}

We require information from authors about some types of materials, experimental systems and methods used in many studies. Here, indicate whether each material, system or method listed is relevant to your study. If you are not sure if a list item applies to your research, read the appropriate section before selecting a response.

Materials \& experimental systems

n/a Involved in the study

Х $\square$ Antibodies

Х Eukaryotic cell lines

$\bigotimes \square$ Palaeontology

Methods

$\bigotimes \square$ Animals and other organisms

$\square$ \uman research participants

$\bigotimes \square$ Clinical data

\section{Human research participants}

Policy information about studies involving human research participants

Population characteristics See above. 


\section{Recruitment}

Ethics oversight
Participants were approached in public spaces by trained survey staff, who were briefed on our sampling strategy (as described above). Periodic analysis of sample demographics was conducted by the project leader (Marshall) during each sampling period, and staff were advised if/when any demographic biases were observed (e.g. for age, gender), and if necessary, were instructed to modify their participant selection tactics.

This research involving human participants was reviewed and approved by the CSIRO Social Science Human Research Ethics Committee and was conducted in accordance with the Australian National Statement on Ethical Conduct in Human Research (2007).

Note that full information on the approval of the study protocol must also be provided in the manuscript. 